Journal of Machine Engineering, 2020, Vol. 20, No. 4, 139-151

ISSN 1895-7595 (Print) ISSN 2391-8071 (Online)

Received: 04 September 2020 / Accepted: 02 November 2020 / Published online: 29 November 2020

damping, friction damper, glass gatherer robot

\author{
Marek STEMBALSKI ${ }^{1 *}$ \\ Andrzej ROSZKOWSKI ${ }^{1}$ \\ Waclaw SKOCZYNSKI $^{1}$ \\ Pawel TUREK ${ }^{1}$ \\ Rafal FENC ${ }^{1}$
}

\title{
ANALYSIS OF GLASS GATHERER ROBOT'S VIBRATION DAMPING USING THE ORIGINAL AND MODIFIED DESIGN OF THE FRICTION DAMPER
}

\begin{abstract}
This paper presents the results of tests carried out on the glass robot's lance equipped with a prototype friction damper. Two ways of mounting the damper (the original design and the modified design) are described. A series of experimental tests were carried out for each of the ways of mounting to determine the lance operating conditions at which the damper worked most efficiently. Resonance curves were determined for each of the designs and it was found that the modified structure reduced vibrations to a greater degree, which clearly indicates that the modified solution ensures a higher vibration damping efficiency.
\end{abstract}

\section{CHARACTERISTICS OF GLASS GATHERER ROBOTS}

Work conditions in glass works are usually very difficult and the employees there are exposed to a very high health risk. Therefore it is natural to limit the number of people working in such difficult conditions. The main task of glass robots is to take liquid glass from the furnace and transfer it to a forming device (Fig. 1). The robot's essential element which has direct contact with the liquid glass is a ball located at the end of a relatively long lance. In order not to overload the robot kinematic nodes, the cross sections of the lance must be as small as possible. This, however, results in the generation of excessive lance vibrations during the manufacturing process (i.e. collecting liquid glass on the ball and transferring it to the forming device) [1]. The vibrations of the ball disturb the work of the robot and adversely affect the quality of the manufactured product. The vibrations result in an uneven distribution of the liquid glass on the surface of the ball and cause the premature dripping of the liquid glass into the form, whereby the glass mass cools unevenly inside

\footnotetext{
${ }^{1}$ Wroclaw University of Science and Technology, Department of Machine Tools and Mechanical Technologies, Wroclaw, Poland

*E-mail: marek.stembalski@pwr.edu.pl https://doi.org/10.36897/jme/129926
} 
the form and the thermal balance is disturbed during the solidification of the material. Consequently, the manufactured product has surface defects resulting in the deterioration of its strength properties and adversely affecting its aesthetic value.

Research on the vibrations of glass lance robots has been conducted for many years at the Faculty of Mechanical Engineering of Wroclaw University of Technology [2-5]. It has been found that the vibrations displacement arising during the manufacturing process are caused by the inertial forces of the robot's end-effectors. The forces are critical when accelerating, braking and changing the direction of movement (turning) of the end-effectors. The easiest way to minimize such vibrations would be to increase the stiffness of the robot's arms, unfortunately at the expense of increasing their weight. This type of solution would be highly unprofitable as it would involve the use of drives with higher power and in many cases it would be necessary to limit the speed of movement of the robot's arms. In industrial conditions replacing the entire glass robot is out of the question because this would necessitate stopping the entire production line for a certain period.

Through laboratory and industrial tests of the robot's supporting structure it has been found that usually one frequency dominates in the vibration spectrum. It is a low frequency associated with the local vibrating system, i.e. the robot's lance with the liquid glass transporting ball at its end. From the technical point of view, the lance is a sleeve of considerable length (because of the high temperature the robot must be some distance away from the furnace), with an internal axial hole for its cooling. This type of element is very susceptible to high vibration amplitudes. Various systems are used to suppress such vibrations. Generally, the suppressors can be classified into three types: passive, semi-active and active.

The use of a particular type of a suppressor is to a large extent determined by the operating conditions. High temperatures and industrial pollution effectively eliminate the possibility of using mechatronic systems based on, e.g., piezoelectric components. An interesting and relatively simple solution is to use a friction damper [6]. Its design usually makes it possible to mount it directly on the robot's lance and no external power supply is required for its operation. Friction dampers dissipate energy through the interaction of their friction surfaces with the contacted body. Many different friction damper designs are described in the literature [7-13], but their use is mainly connected with building infrastructure.

An interesting example of a semi-active damper used on the robot's arm can be found in $[14,15]$. The damper incorporates a magnetorheological damper. Other examples of the use of magnetorheological suppressors can be found in [16-19]. From the point of view of the active control of damping parameters, active dampers are the best solution. Examples of such dampers can be found in [20-29].

The dampers act directly on the vibrating system, but it is necessary to implement an appropriate algorithm for controlling the damper's response to changing vibration amplitudes. For this purpose, systems based on real-time processors are required. But this entails significant costs and the need for additional electrical and electronic equipment which cannot be used directly on the lance (due to dust, industrial pollution and high temperature). Nevertheless, in the literature one can find examples of semi-active and active systems used for damping vibrations [30, 31]. 
There are several ways to reduce the gatherer robot's arm amplitude of vibration of the robot arm used to transport the liquid glass. One of them is to increase the stiffness of the lance by reducing the diameter of the hole for coolant supplying, or by increasing the cross section of the lance. However, increasing the size of this section would result in an increase in the weight of the working unit, which in turn would cause an increase in the fundamental frequency of natural vibration. Furthermore, this solution is associated with interference in the structure of the ball gatherer. Another way of reducing the amplitude of the vibrations of the lance is changing the method of control. This can be achieved by reducing the velocity and acceleration of individual units of the robot. Additionally, smooth deceleration of the ball above the moulding device and smooth start at the place of gathering of the molten glass may be introduced. However, this is dependent on the capabilities of the control system. Each of the proposed solutions would involve a direct interference in the structure of the robot or the control system (substitute of the controller, drives).

This paper presents a concept of a friction damper mounted directly on the robot's lance. On the basis of the literature on the subject and own experience the authors propose a novel design solution in two versions (original and modified). The results of laboratory tests for both solutions, validating the system's correct operation and effective reduction of vibrations, are presented.

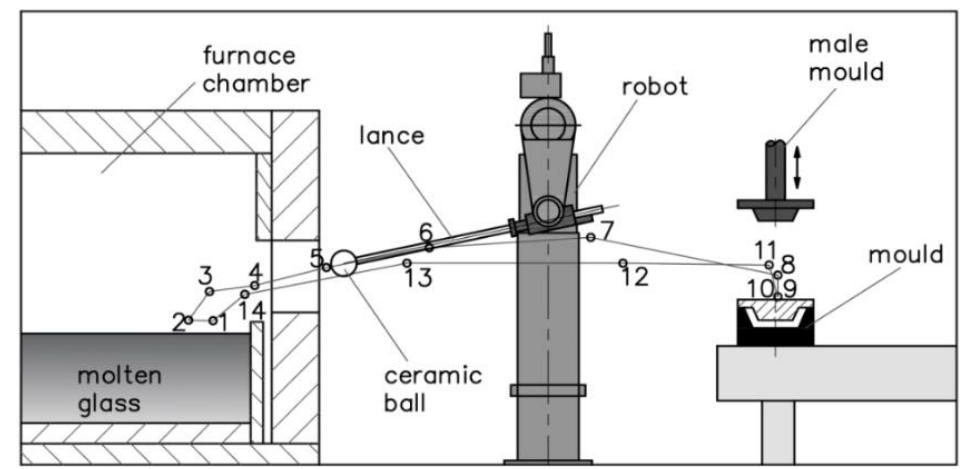

Fig. 1. Diagram of a robotised glassware manufacturing process: $1-4$ gathering of molten glass from the furnace; 4-8 transport of glass from the furnace above the moulding device; 8-10 movement of the ball above the moulding device (dripping of the molten glass); 10-14 return of the ceramic ball to the tank furnace [1]

\section{ORIGINAL DESIGN OF THE DAMPING SYSTEM MOUNTED ON THE GLASS GATHERER ROBOT'S LANCE}

After the friction damper had been designed and built, it was necessary to ensure its attachment to the lance in a way not interfering in the latter's structure. Figure 2 shows a structural diagram of the friction damper mounted on the glass gatherer robot's lance on the laboratory stand. Damper friction rings $(3,4)$ are mounted between the fixing elements: thrust disc (2) and clamping nut (7). The main task of these elements is to transfer the rotational movements of the lance cross-sections during the transverse vibration of the ball gatherer arm to the damper's rings. The entire damping system is attached to the lance by means of clamps (8). 


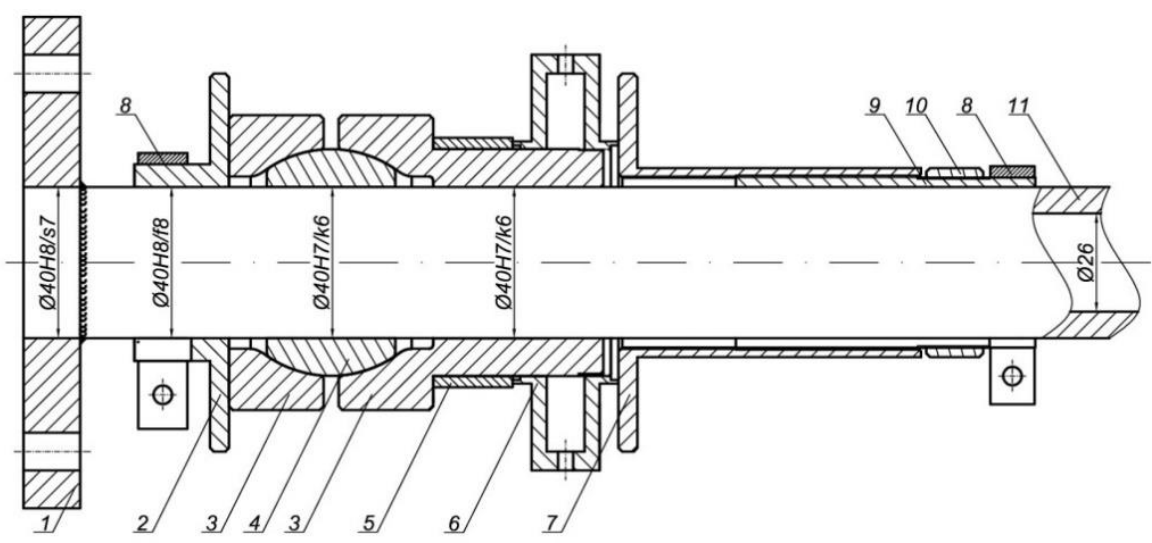

Fig. 2 Structural diagram of the damping system mounted on the glass gatherer robot's lance - original design: 1) flange securing the lance to the cast iron block, 2) thrust disc, 3) outer rings of the friction damper, 4) inner ring of the friction damper, 5) spacer ring, 6) uniaxial strain gauge, 7) clamping nut, 8) clamps, 9) clamping sleeve,

10) lock nut, 11) glass gatherer robot's lance

The literature $[32,33]$ and the research conducted at the Institute of Production Engineering and Automation at Wroclaw University of Technology $[4,34]$ indicated that the damping properties of the described structure may vary depending on the value of the preload force exerted by the damper rings. This meant that it was possible to adjust this force. For this purpose clamping nuts (7) and clamping sleeve (9) were used. In addition, lock nut (10) was used so that the clamping nut would not unscrew during the application of forced dynamic loads and the introduced preload force would not decrease. Moreover, the value of the introduced preload force had to be controlled. For this purpose uniaxial tensometric dynamometer (6) enabling the continuous measurement of the preload force was designed and built.

In the initial designs [35] instead of spacer ring (5) a thrust ball bearing had been used to reduce the friction torque during the application of the preload force. But preliminary tests had shown a negative impact of this bearing on the damping properties of the friction damper. As the force acts on the lance the lateral movements of the latter should be transferred to the friction damper's rings. But the ball bearing had not provided adequate rigidity. Relative movements had not been performed by the friction damper's rings, but by the bearing balls and raceways. This had weakened the dissipation of vibration energy due to the structural friction of the friction damper elements. Therefore the use of the above-mentioned bearing was abandoned and the structure of the longer damper ring spacer was modified by introducing ring (5) instead of the bearing.

The results of tests of the vibration damping efficiency of the glass gatherer robot's arm are reported in detail in [36].

\section{MODIFIED DESIGN OF THE DAMPING SYSTEM MOUNTED ON THE GLASS GATHERER ROBOT'S LANCE}

After analysing the impact of the original design of the friction damper on the reduction of vibrations of the glass gatherer robot's arm [36], it was found that the vibration 
level obtained may depend on many factors, including damping by the material system. The design of the friction damper used, as well as from additional fasteners that increase the number of friction joints in the system, thereby increasing the structural friction. In addition, the results obtained may be affected by the quality of the fit obtain between the lance and the elements transferring the rotation of this lance's cross-sections. These elements in the structure are: clamping nut, clamping disc and clamps. For this reason, it was decided to modify the design of the damping system and the lance. This change was intended, as far as possible, to reduce the number of intermediate elements between the lance and the damper, thus reducing the number of friction joints compared to the original design.

The design of the lance, flange and damping system has been modified in relation to the existing real model. In order to provide better stiffness and a larger area of connection of the cast iron block and the lance, the diameter and thickness of the lance flange have been increased. The surface on which the lance was attached to the cast iron block was scraped to increase the contact surface of the flange to the cast iron block. A hole was made in the flange with a tight fit, into which the lance was inserted, and then both elements were welded together. In the new design, the length of the lance and the diameter of the internal hollow hole are retained in relation to the actual lance of the glass gatherer robot. The new lance design with a flange is shown in Fig. 3.

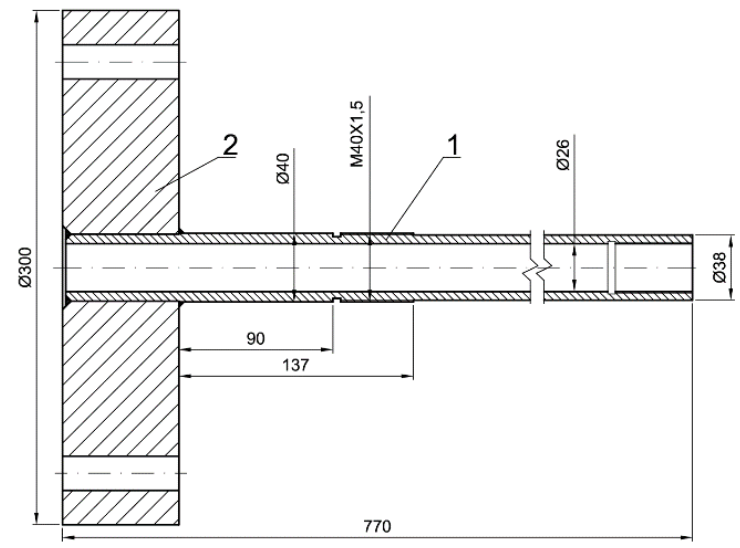

Fig. 3. Modified design of the glass gatherer robot's lance with a flange: 1) Lance, 2) Flange

A thread was made in the lance, adapting it to the design dimensions of the damper. On the one hand, this eliminated the mounting sleeve from the design, while on the other, the threaded connection made it possible to introduce changes in the preload force of the damper rings. Because of the thread that was added, it was necessary to slightly weaken the cross-section of the lance, slightly reducing its outer diameter so that it was possible to place a damper clamping nut on the thread. The modified design also eliminates the mounting disc and clamps, resting the damper rings directly on the lance flange.

The main task of the measurement bench described was to check the effectiveness of the friction damper. Figure 4 shows the diagram of the friction damper and how it is attached to the lance. On one hand, the damper rings rested directly on the lance flange (7), 
while on the other hand they were pressed with a thrust disc (4). To avoid unscrewing the disc during operation of the system at resonance frequencies, when the vibration amplitudes are greatest, a lock nut (5) was placed behind the disc. A strain gauge (3) was placed on the longer outer ring of the friction damper. Its task was to measure the clamping force of the damper rings. A spacer ring (2) was used between the dynamometer and the bearing surface of the longer damper ring.

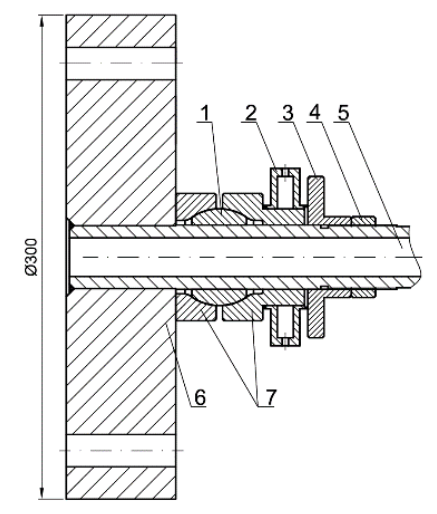

Fig. 4. Friction damper mounted on the arm of the glass gatherer robot - modified design: 1) damper's internal spherical ring, 2) dynamometer, 3) thrust disc, 4) lock nut, 5) glass gatherer robot's lance, 6) lance flange,

7) spherical outer rings of the friction damper

\section{MEASUREMENT BENCH}

Figure 5 presents an experimental bench for testing the impact of a modified damping structure on the vibration level of a lance with an attached substitute weight.

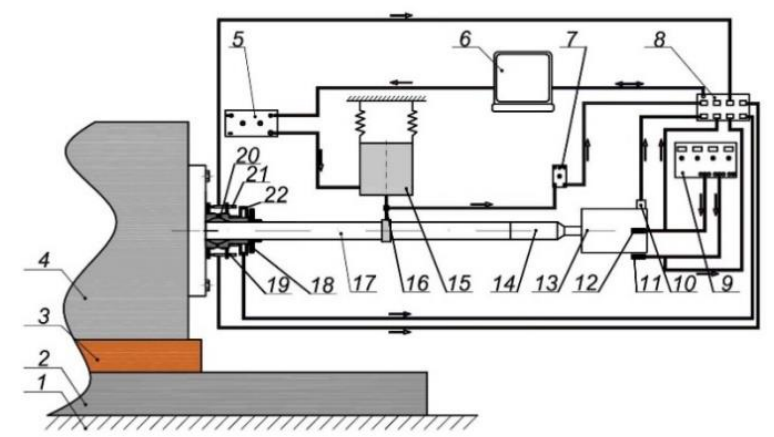

Fig. 5. Diagram of an experimental bench for testing the impact of the friction damping on the vibration level of a lance with an attached substitute weight

Where: 1) foundation, 2) steel plate, 3) wooden sleepers, 4) cast iron block with a weight of about $1.2 \mathrm{t}$, 5) Brüel\&Kjaer 2706 power amplifier, 6) portable computer, 7) Brüel\&Kjaer 2635 charge amplifier, 8) Quantum MX840 multi-channel measuring system, 9) NDN DF 1731SB5A stabilized power supply, 10) B12 induction accelerometer, 11) optoNCDT 1300 optical displacement sensor - measurement of vertical displacement, 
12) optoNCDT 1300 optical displacement sensor-measurement of horizontal displacement, 13) substitute weight, 14) lance adapter, 15) Brüel\&Kjaer 4809 electrodynamic sensor, 16) Brüel\&Kjaer 8230 C-003 piezoelectric force gauge, 17) glass gatherer robot's lance, 18) thrust disc, 19) VIS MDKa - E1 inductive displacement sensor, 20) friction damper, 21) VIS MDKa - E1 inductive displacement sensor, 22) single-axis strain gauge [37].

The cast iron block (4) was placed on wooden sleepers (3). The entire structure of the test stand was placed on a reinforced concrete floor (2). The glass gatherer robot's lance (17) was attached to the cast iron block (4). The replacement weight (13) was screwed to the end of lance by transitional element (14).

The electrodynamic exciter (15) was attached to the lance with a sleeve. The powered signal came from the power amplifier (5). The input signal sent to the power amplifier was generated from a computer sound card (6). Software algorithm to generate the required sweep signal was developed in the Matlab environment. In this program algorithm, the user specified the signal duration, the start and end frequency, and the frequency shift step. The signal generated in this way was saved in the audio file with the "wav" extension. The signal from the computer sound card was sent to the power amplifier (5), and then to the exciter (11).

The exciter (11) generated vibrations that were measured on the replacement weight. The vibration displacement of the replacement weight was measured by optical displacement sensors in the horizontal and vertical directions (12). The signals from the sensors went to the Quantum measurement system (8). Additionally, an induction accelerometer (10) was placed on the substitute mass (13). The signal from the accelerometer (10) was used to develop the amplitude-frequency characteristics, and then to determine the damping decrement.

During the tests, the relative displacements between the rings of the friction damper were recorded. Inductive transducers were used for this measurement (21). Their signals were recorded by the Quantum measurement system (8). In this system, with the use of a uniaxial piezoelectric dynamometer (16), the exciting force exerted by the electrodynamic exciter on the tested lance was also recorded. Additionally, the initial pressure force of the rings of the described damper was measured. For this purpose, a strain gauge (25) was used. The signal from the force sensor was also sent to the measuring system (8).

During the experiment, the lance was subjected to harmonic extortion. The frequency band of the excitation for $9.5 \mathrm{~kg}$ and $5 \mathrm{~kg}$ equivalent masses was $8-20 \mathrm{~Hz}$. The execution time was 240 seconds. Measurement signals in all channels were sampled with a frequency of 1200 samples per second. During the tests, the response of the system was checked with different values of the preload force of the damper rings and for different values of the exciting force acting on the robot lance.

\section{DYNAMIC CHARACTERISTICS OF THE LANCE WITH A BALL GATHERER}

On the basis of the tests conducted in selected frequency bands, amplitude and frequency characteristics of the lance with the replacement weight were designated. 
The operating conditions at which the friction damper has the best damping properties were also specified. Measurements were made with replacement weights $9.5 \mathrm{~kg}$ and $5 \mathrm{~kg}$ attached. In both cases, the maximum value of the exciting force was set on the power amplifier that powered the electrodynamic exciter. This value was determined experimentally. The inductor was attached to the lance in such a place so that the displacements obtained were within the acceptable range of the exciter membrane's displacement. These values define the maximum amplitude at which the inductor can operate without damage. For each value of the substitute weight, three levels of excitation forces were set: maximum of about $34 \mathrm{~N}$, medium - about $23 \mathrm{~N}$ and the smallest - about $18 \mathrm{~N}$.

The experimentally determined lance suppression coefficients for the substitute weight of $9.5 \mathrm{~kg}$ attached and for different values of the excitation force are presented in Fig. 6. During a single measurement cycle, the initial pressure value was introduced into the Thrust disc. Then the measurement was performed, during which the lance was subjected to harmonic excitation in the $8-20 \mathrm{~Hz}$ frequency band. After saving the data from the measuring sensors, the preload force was increased and another measurement was carried out. For each of the excitation forces and each value of preload force, the measurement was repeated 5 times. For each measurement, the average value and standard deviation were calculated.

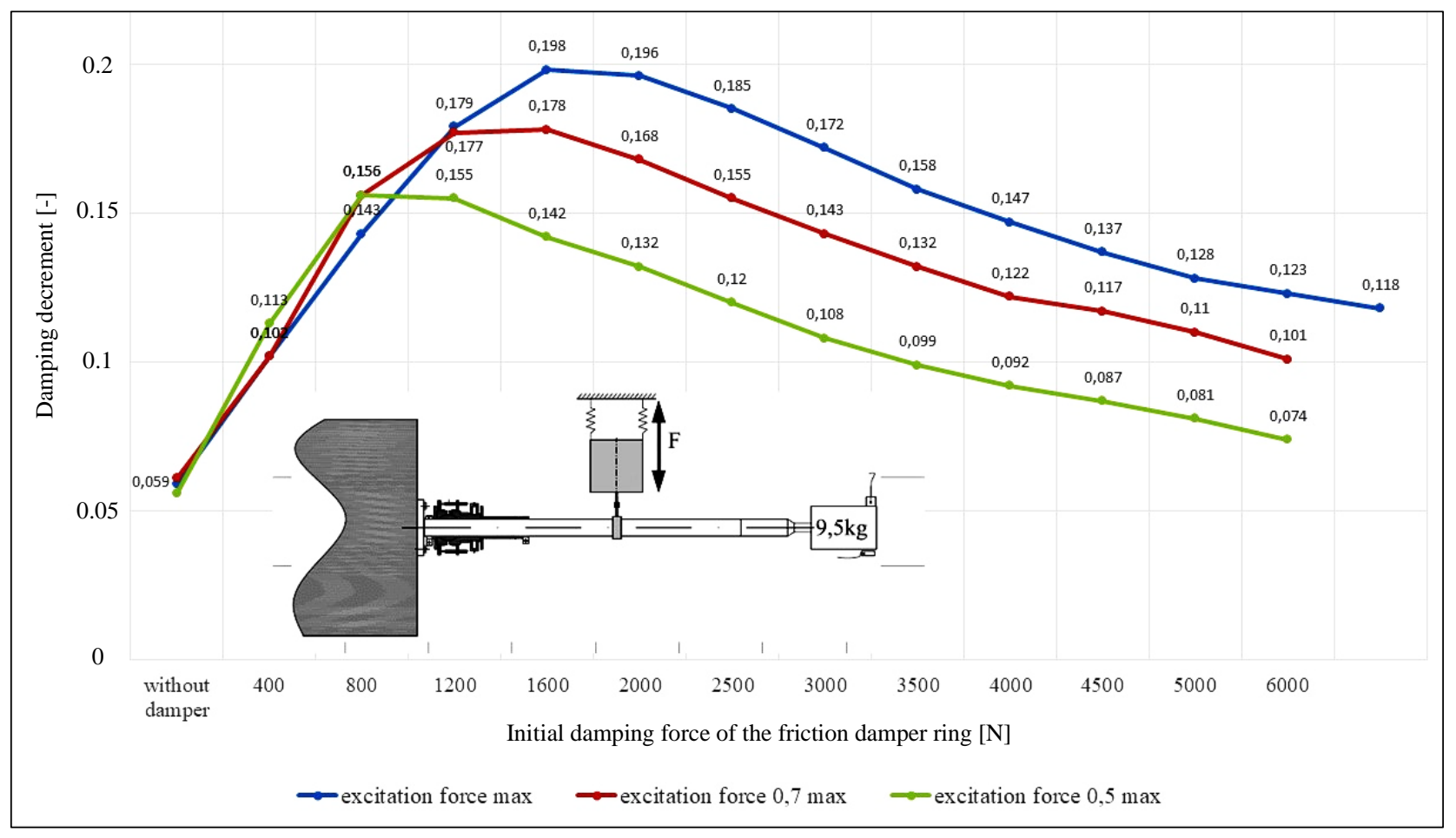

Fig. 6. Sample graphs of the dependence of the decrement value of lance damping on the preload force of the spherical friction damper rings and the variable value of the excitation force for the attached substitute weight of $9.5 \mathrm{~kg}$

From the graphs in Figure 6 it can be seen that for the test system with the lance, there is an optimum value of the preload force at which the damping of the whole system is greatest. These values change depending on the value of excitation force. The higher 
the exciting force, the greater was also the preload force at which the system had the best damping properties. These results also confirm that the friction damper operates more effectively with the greater amplitude of the movements of the robot arm.

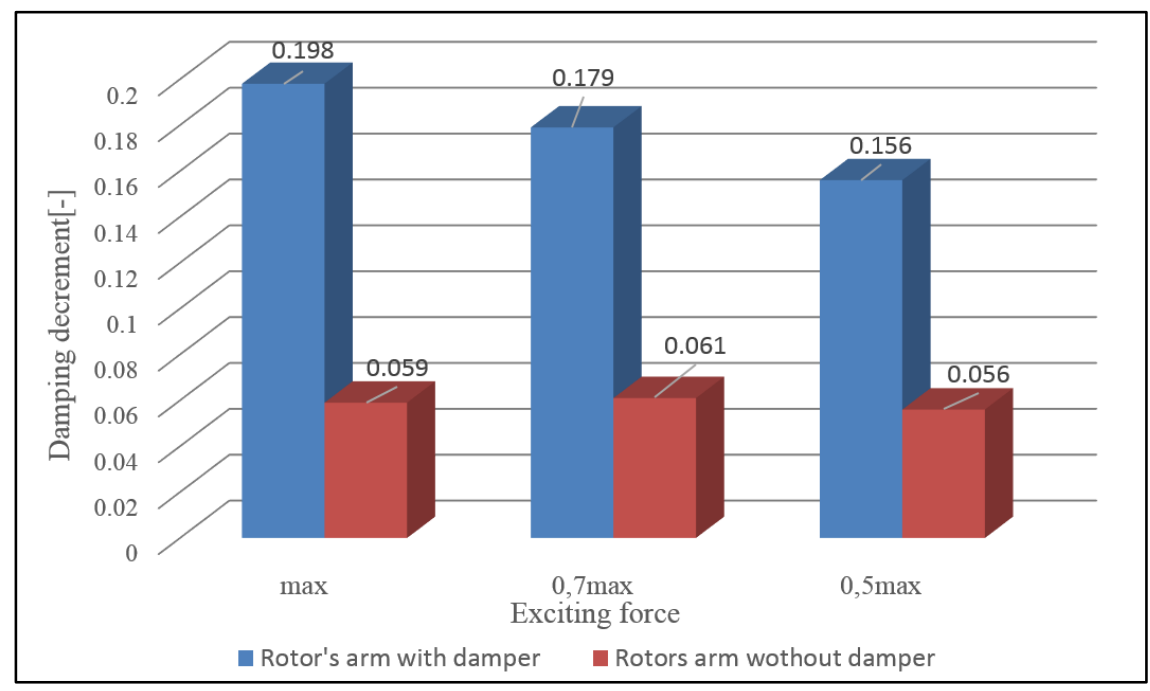

Fig. 7. Dependence of the decrement value of lance damping on the preload force of the spherical friction damper rings and the variable value of the excitation force for the attached substitute weight of $9.5 \mathrm{~kg}$

In order to assess in a simple way the impact of the friction damper on the damping of vibration of the glass gatherer robot's lance, vibration displacement of the tip of the lance with the substitute weight was measured. Based on the measured waveforms of vibration, maximum resonance amplitudes for clamping forces of the damper's rings were compared, at which the system had the greatest damping decrement. Figure 8 illustrates a summary of the resonant amplitudes of the lance tip at different forces for the system without a damper and with the friction damper mounted.

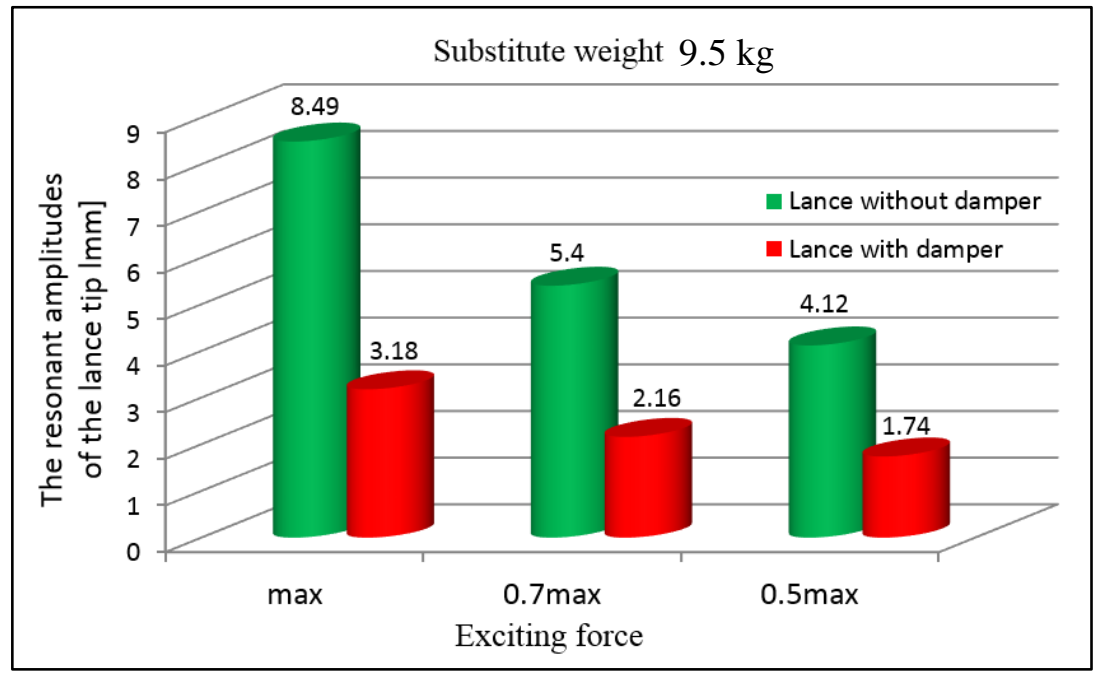

Fig. 8. Comparison of resonance amplitudes of lance displacement for the attached weight of $9.5 \mathrm{~kg}$ under the conditions of the most favourable initial pressure of the friction rings 
The use of a friction damper resulted in a significant reduction in the vibration amplitude of the lance. For the substitute weight of $9.5 \mathrm{~kg}$, the amplitude decreased by $57-62 \%$ depending on the value of the excitation force.

\section{COMPARISON OF DYNAMIC CHARACTERISTICS OF THE ORIGINAL AND MODIFIED DESIGN}

Tests were carried out for both designs to determine the impact of the friction damper on the reduction of the amplitude of vibrations of the glass gatherer robot's arm. In both cases, the measurements were carried out using the same substitute weights, with the same excitation forces and using the same measurement path.

Comparing the test results of both designs, the damping decrement determined at a specified level of excitation force and preload forces at which the system showed the largest damping decrement was analysed. Figure 9 summarises the test results for two design solutions.
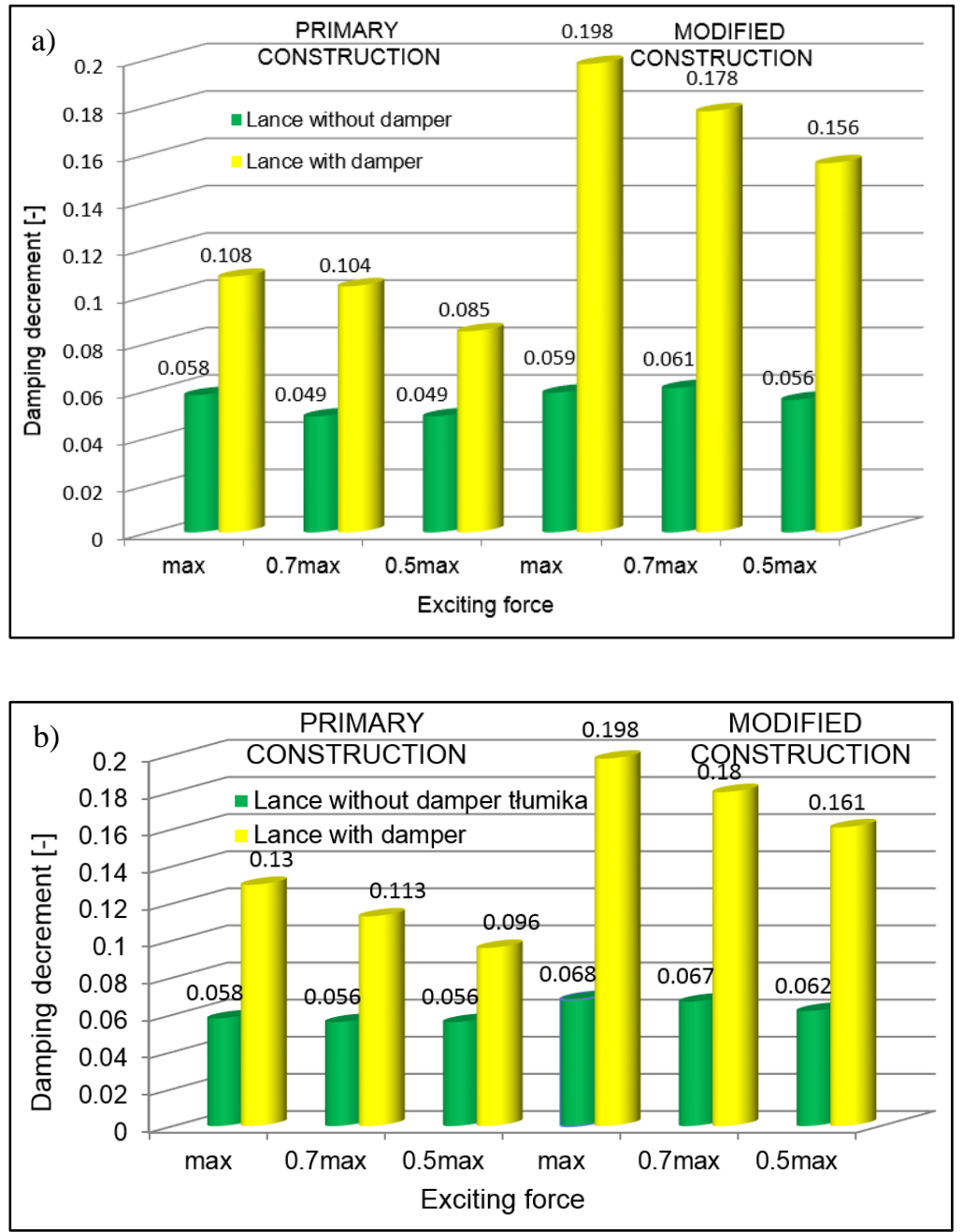

Fig. 9. Comparison of damping decrement values for the original and modified lance design with substitute weight: a) $9.5 \mathrm{~kg}$, b) $5 \mathrm{~kg}$ 
For the discussed designs, the values of resonance amplitudes for the lance system with and without a damper were also compared (Fig. 10). This comparison was made based on the signal received from the laser displacement sensor.
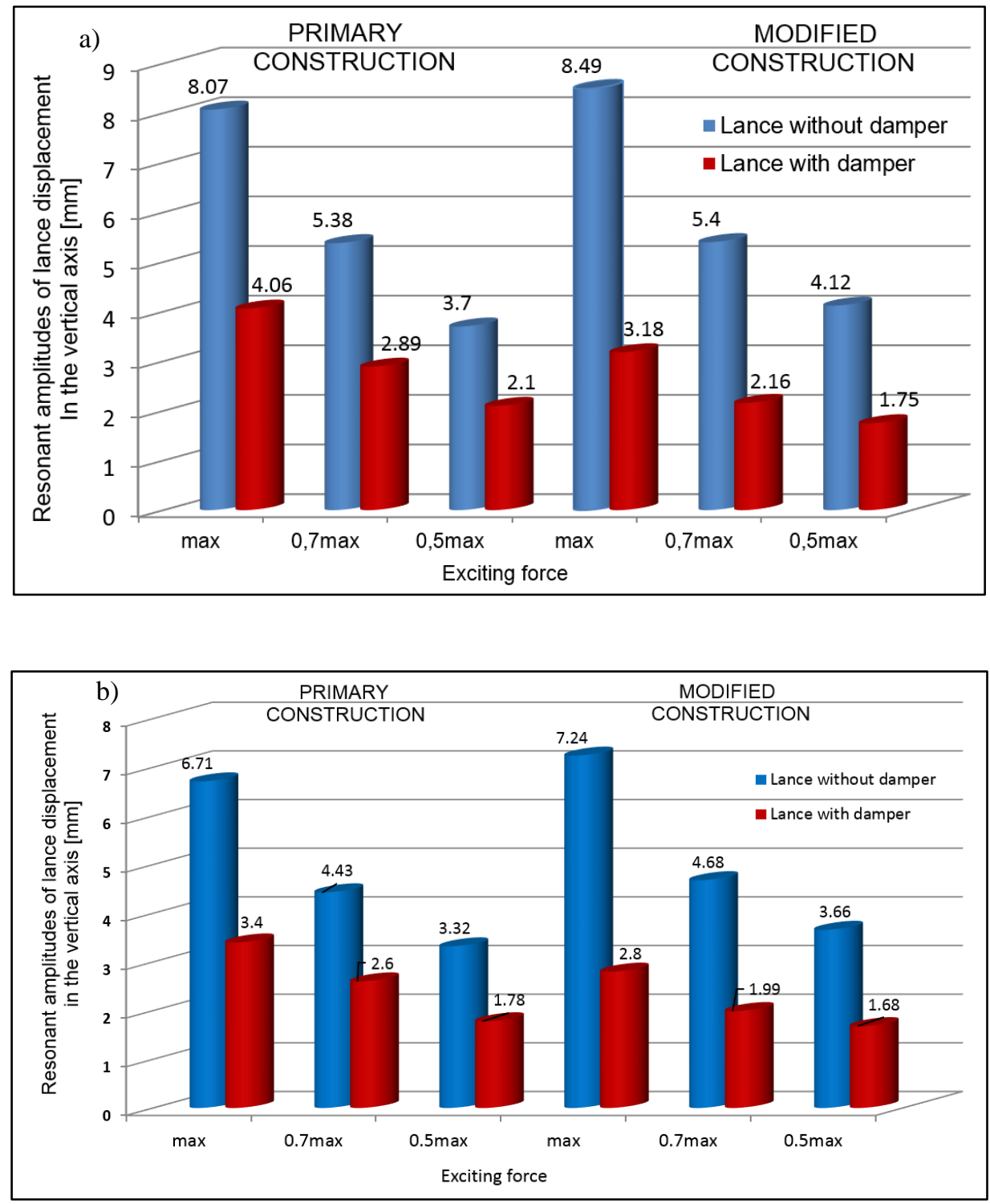

Fig. 10. Comparison of resonance amplitudes of vibration displacement of the lance tip of the system with and without a damper for substitute weights: a) $9.5 \mathrm{~kg}$, b) $5 \mathrm{~kg}$

\section{CONCLUSION}

In this paper, two measurement benches are presented used to determine the impact of using a friction damper on the reduction of vibration amplitudes of a glass gatherer robot's arm. The modifications introduced in the lance design and the system mounting the damper on the lance allowed to increase relative movements between the silencer rings at the same lance deflections. This allowed to increase the damping efficiency of the system 
compared to the original design. The developed method of passive damping of the glass gatherer robot's lance, based on a prototype friction damper with the instrumentation constructed, allows for making an effective impact on the level of vibration of the robot arm. The tests confirmed the effectiveness of this method for harmonic forces. Tests of the dynamic characteristics of the lance with a friction damper has allowed to determine the optimal preload forces of the damper rings, for which the system possessed the best damping properties. The values of these forces changed depending on the level of vibration and the values of substitute weights. At the most favourable operating parameters of the damper, the damping decrement increased almost four times compared to a system without a damper. The use of a friction damper resulted in more than a double reduction of the resonant vibration amplitude of the lance. It must therefore be concluded that the friction damper performs its functions effectively.

\section{REFERENCES}

[1] CHOROSZY T., MAREK B., ROSZKOWSKI A., SKOCZYŃSKI W., SZYMKOWSKI J., 2005, Measurement of Vibrations of Glass Robots During the Implementation of the Technological Cycle, Mechanical Review, LXIV, 9, 196-199.

[2] SKOCZYŃSKI W., KRZYŻANOWSKI J., 2003, Dynamic Properties Testing of Glazier's Robot Structure, Modern Trends in Manufacturing, Second International CAMT Conference, Wroclaw, 20-21 February 2003, Oficyna Wydawnicza PWr., 335-342.

[3] ROSZKOWSKI A. 2008, Possibilities of Actively Influencing the Vibration Level of the Robot's Executive Team, $\mathrm{PhD}$ thesis, Wroclaw University of Science and Technology, Poland.

[4] ROSZKOWSKI A., CHOROSZY T., SKOCZYŃSKI W., KRZYŻANOWSKI J., MAREK B., 2005, The Concept of the Test Stand for Measuring Vibration of a Glass Robot Lance with Adjustable Dampers, Mechanical Review, LXIV, 9, 240-244.

[5] ROSZKOWSKI A., GÓRSKI P., CHOROSZY T., SKOCZYŃSKI W., KRZYŻANOWSKI J., 2006, Numerical Analysis and Experimental Verification of the Properties of the GLASS Robot Lance, Open-Mining, XLVIII, 7/8, 113-117.

[6] STEMBALSKI M., SKOCZYŃSKI W., ROSZKOWSKI A., 2018, Semi-Active Vibration Damping System, Polish Patent No 227880, PCT No. P. 410145 from 18.11.2014 Publ. 01/03/2018.

[7] MUllA I.H., BELEV B., 2002, Performance of Steel Frames with a New Friction Damper Device Under Earthquake Excitation, Engineering Structures, 24, 365-371.

[8] ANKIREDDI S., YANG H.T.Y., 2000, Directional Mass Dampers for Buildings Under Wind or Seismic Loads, Journal of Wind Engineering and Industrial Aerodynamics, 85/2, 119-144.

[9] DENG K., PAN P., WANG C., 2013, Development of Crawler Steel Damper for Bridges, Journal of Constructional Steel Research, 85, 140-150.

[10] GOLAFSHANI A.A., GHOLIZAD A., 2009, Friction Damper for Vibration Control Offshore Steel Jacket Platforms, Journal of Constructional Steel Research, 65, 180-187.

[11] HONG-NAN L., GANG L., 2007, Experimental Study of Structure with “Dual Function” Metallic Dampers, Engineering Structures, 29/8, 1917-1928.

[12] KAREEM A., 1997, Modelling of Base-Isolated Building with Passive Dampers Under Winds, Journal of Wind Engineering and Industrial Aerodynamics, 72, 323-333.

[13] QU W.L., CHEN Z.H., XU Y.L., 2001, Dynamic Analysis of Wind-Excited Trust Tower with Friction Dampers, Computers and Structures, 79, 2817-2831.

[14] ROSZKOWSKI A., BOGDAN M., SKOCZYŃSKI W., MAREK B., 2008, Testing of the Viscosity of an MR Fluid in the Magnetic Field, Measurement Science Review, 8/3-3, 58-60.

[15] ROSZKOWSKI A., SKOCZYŃSKI W., 2008, Glass Making Robot, Magnetorheological Fluid Damper, Inżynieria Maszyn, 13/3-4, 122-132, (in Polish).

[16] BOSSIS G., LACIS S., MEUNIER A, VOLKOVA O., 2002, Magnetorheological Fluids, Journal of Magnetism and Magnetic Materials, 252, 224-228. 
[17] HOGSBERG J., KRENK S., 2008, Energy Dissipation Control of Magneto- Rheological Damper, Probabilistic Engineering Mechanics, 23/1-2, 188-197.

[18] KYUNG-IN J., BYUNG-KNOW M., JONGWON S., 2011, A Behavior Model of Magnetorheological Fluid on Direct Shear Mode, Journal of Magnetism and Magnetic Materials, 323/10, 1324-1329.

[19] ZHU W.Q., DONG M.L.L., 2004, Semi-Active Control of Wind Excited Building Structures Using MR/ER Dampers, Probabilistic Engineering Mechanics, 19/3, 279-285.

[20] CAO H., LI Q.S., 2004, New Control Strategies for Active Tuned Mass Damper System, Computers\& Structures, $82 / 27,2341-2350$.

[21] CHAE-WOOK L., 2008, Active Vibration Control of the Linear Structure with an Active Mass Damper Applying Robust Saturation Controller, Mechatronics, 18/8, 391-399.

[22] SODANO H.A., INMAN D.J., 2007, Non - Contact Vibration Control System Employing an Active Eddy Current Damper, Journal of Sound and Vibration, 305/4-5, 596-613.

[23] CHAEWOOK L., 2008, Active Vibration Control of the Linear Structure with an Active Mass Damper Applying Robust Saturation Controller, Mechatronics, 18/8, 391-399.

[24] KASANDRA M.E.F. MENDOZA H., KIRK R.G., WICKS A., 2004, Reduction of Subsynchronous Vibrations in a Singledisk Rotor Using an Active Magnetic Damper, Mechanics Research Communications, 31/6, 689-695.

[25] KORLIN R., STAROSSEK U., 2007, Wind Tunnel Test of an Active Damper for Bridge Decks, Journal of Wind Engineering and Industrial Aerodynamics, 95/4, 267-277.

[26] KOZANECKA D., KOZANECKA Z., ŁAGODZIŃSKI J., 2011, Active Magnetic Damper in a Power Transmission System, Communications in Nonlinear Science and Numerical Simulation, 16/5, 2273-2278.

[27] OZBULUT O.E., BITARAF M., HURLEBAUS S., 2011, Adaptive Control of Base-Isolated Structures Against Near - Field Earthquakes Using Variable Friction Dampers, Engineering Structures, 33/12, 3143-3154.

[28] XU Y.L., 1996, Parametric Study of Active Mass Dampers for Wind-Excited Tall Buildings, Engineering Structures, 18/1, 64-76.

[29] YOSHIDA H., HIROSE E., SAKAGAMI Y., 1999, Active Damper of Magnetically Suspended Pellet for Laser Fusion Scheme, Fusion Engineering and Design, 44/1-4, 467-470.

[30] ORMAN M., SNAMINA J., 2009, Comparison of the Effectiveness of Semi-active and Active Vibration Dampers on the Example of Ropes, Journal of Technical Mechanics, 106/3, 71-83.

[31] OSIŃSKI Z., 1997, Vibration Suppression, PWN Scientific Publishing House, Warsaw.

[32] SKUP Z,. 2010, Nonlinear Suppression Phenomena, Publishing House of Warsaw University of Technology, Warsaw.

[33] SKUP Z., 2010, Analysis of Damping of Vibrations Through a Frictional Damper, Journal of Theoretical and Applied Mechanics, 48, 465-478.

[34] STEMBALSKI M., PREŚ P., SKOCZYŃSKI W., TUREK P., 2018, Modelling of a Glass Gatherer Robot Arm with Frictional Damper, Journal of Machine Engineering, 18/4, 127-140.

[35] STEMBALSKI M., SKOCZYŃSKI W., ROSZKOWSKI A., 2012, Numerical Model of Frictional Damper for Glass Making Robot Lance, Journal of Kones, 19/1, 391-398.

[36] STEMBALSKI M., SKOCZYŃSKI W., ROSZKOWSKI A., PREŚ P., 2017, Testing the Vibration Damping of a Glass Gatherer Robot Arm Using a Friction Damper, Archives of Civil and Mechanical Engineering, 17/2, 240-248.

[37] STEMBALSKI M., 2013, Modeling and Testing of a Friction Damper Applied to a Glass Robot, PhD Thesis, Wroclaw University of Science and Technology, Poland. 